\title{
Avaliação de impactos ambientais na APP do Rio Paranaíba e inferências para mitigação
}

As Áreas de Preservação Permanente (APP), por meio da vegetação ripária exercem papel fundamental na rede de drenagem, estabilizando margens, formando corredores ecológicos, protegendo a biodiversidade e os mananciais, e ainda regulando o fluxo de água e nutrientes. O presente estudo teve como objetivo avaliar os principais impactos ambientais existentes na área de APP do rio Paranaíba (perímetro urbano), no município de Patos de Minas e apontar inferências para mitigação dos impactos e recuperação ambiental das áreas degradadas. Para isso, foi utilizada a matriz adaptada de Leopold com o intuito de avaliar os impactos ambientais quanto ao seus principais atributos e interferências nos meios físico, biótico e antrópico. Os impactos negativos, de origem antrópica, identificados na APP do rio Paranaíba, mais frequentes foram: erosão/assoreamento, presença de espécies exóticas/invasoras, lançamento de esgoto e disposição de resíduos sólidos. Os fatores que mais impactaram o meio físico, com alta magnitude e alta importância para os aspectos considerados foram: a disposição de resíduos sólidos e o desbaste. Dos impactos observados, aqueles que mais afetaram o meio biótico correspondem ao fogo, presença de espécies exóticas, desbastes e o lançamento de esgoto, com alta magnitude e alta importância para os atributos deste meio. Em relação ao meio antrópico, os impactos com maior relevância em função da alta magnitude e alta importância para todos os atributos analisados para este meio foram: o lançamento de esgoto, ausência de dissipador final eficiente de drenagem urbana e o desbaste. Os resultados encontrados apontam a necessidade de mitigação dos impactos ambientais e recuperação das áreas onde houve maiores evidências de degradação ambiental.

\section{Environmental impact assessment on the Paranaiba River APP and inferences for mitigation}

The Permanent Preservation Areas (APP), through riparian vegetation, play a fundamental role in the drainage network, stabilizing banks, forming ecologica corridors, protecting biodiversity and springs, and also regulating the flow of water and nutrients. The present study aimed to evaluate the main environmental impacts existing in the APP area of the Paranaíba river (urban perimeter), in the municipality of Patos de Minas and to point out inferences for the mitigation of impacts and environmental recovery of degraded areas. For this, Leopold's adapted matrix was used in order to evaluate the environmental impacts regarding its main attributes and interferences in the physical, biotic and anthropic environments. The most frequent negative impacts, of anthropic origin, identified in the Paranaíba River APP were: erosion/silting, presence of exotic/invasive species, sewage discharge and solid waste disposal. The factors that most impacted the physical environment, with high magnitude and high importance for the aspects considered, were: solid waste disposal and thinning. Of the impacts observed, those that most affected the biotic environment correspond to fire, presence of exotic species, thinning and the release of sewage, with high magnitude and high importance for the attributes of this environment. In relation to the anthropic environment, the most relevant impacts due to the high magnitude and high importance for all the attributes analyzed for this environment were: the release of sewage, absence of efficient final sink of urban drainage and thinning. The results found point to the need to mitigate environmental impacts and recover areas where there was greater evidence of environmental degradation.

Keywords: Riparian zone; Urban areas; Degradation; Leopold's matrix.

Topic: Planejamento Urbano

Reviewed anonymously in the process of blind peer

Eni Aparecida do Amaral (io

Universidade Federal de Uberlândia, Brasil http://lattes.cnpq.br/8537500126906293

http://orcid.org/0000-0002-7125-7845

eni@patosdeminas.mg.gov.br

Andre Rosalvo Terra Nascimento (iD

Universidade Federal de Uberlândia, Brasil

http://lattes.cnpq.br/9748866094633137

http://orcid.org/0000-0002-0112-8511

arnterra@gmail.com

Claudionor Ribeiro da Silva (iD

Universidade Federal de Uberlândia, Brasil

http://lattes.cnpq.br/4808617954565343

http://orcid.org/0000-0003-4542-0933

crs.educ@gmail.com
Received: 06/07/2021

Approved: 29/07/2021

Ana Paula de Oliveira (iD)

Universidade Federal de Goiás, Brasil

http://lattes.cnpq.br/7627235061109618

http://orcid.org/0000-0002-5153-8519

anadeoli@gmail.com

Gabriel Rosa da Silva (iD

Centro Universitário de Patos de Minas, Brasil

http://lattes.cnpq.br/9016122574905223

http://orcid.org/0000-0003-1083-1679

gbr.ambiental@gmail.com
Referencing this:

AMARAL, E. A.; NASCIMENTO, A. R. T.; SILVA, C. R.; OLIVEIRA, A. P.; SILVA, G. R.. Avaliação de impactos ambientais na APP do Rio Paranaíba e inferências para mitigação. Revista Ibero Americana de Ciências Ambientais, v.12, n.7, p.572-584, 2021. DOI: http://doi.org/10.6008/CBPC2179-6858.2021.007.0049

DOI: 10.6008/CBPC2179-6858.2021.007.0049 


\section{INTRODUÇÃO}

Os processos de urbanização vêm sendo acompanhados por profundas alterações no uso e ocupação do solo, os quais resultam em impactos ambientais nas bacias hidrográficas principalmente em suas áreas de proteção. As transformações sofridas pelas bacias em fase de urbanização podem ocorrer rapidamente, e quando não há planejamento na gestão urbana, podem provocar desequilíbrio nos sistemas ambientais interferindo de forma negativa na qualidade de vida da população (ONO, 2008).

Dentro de uma bacia hidrográfica, as matas ripárias exercem papel fundamental na rede de drenagem, a destacar: sustentação do solo nas suas margens, formação de corredores ecológicos, manutenção da biodiversidade, proteção de mananciais, ciclagem de nutrientes e na regulação do fluxo de água (GONÇALVES et al., 2005; MORAIS et al., 2017).

De acordo com Morais et al. (2017), a vegetação ripária, por meio da serapilheira e das raízes das árvores, fornece resistência ao impacto das gotas das chuvas e do escoamento superficial, por proporcionarem maior infiltração da água, reduzindo assim processos de erosão e assoreamento. Essa vegetação funciona como um papel de filtro das águas que sobrevém das partes mais altas da bacia impedindo ou dificultando o carreamento de sedimentos e resíduos para o sistema aquático, contribuindo, dessa forma, para a manutenção da qualidade da água nas bacias hidrográficas.

Neste sentido, Stutter et al. (2021) também destaca essa função das matas ripárias, quando afirma que a vegetação ripária funciona como uma zona de amortecimento de impactos aos recursos hídricos uma vez que as boas condições ciliares das zonas ripárias proporcionam o aumento da resiliência do sistema do canal ripariano às pressões locais ou a montante. Por outro lado, a degradação da condição e função em áreas ribeirinhas leva a resiliência reduzida.

As zonas ripárias estão enormemente degradadas em todo o mundo devido às atividades humanas e às mudanças no uso da terra nas áreas adjacentes (WANG et al., 2020). A destruição das matas ripárias e a conversão destas áreas em outros usos e ainda as formas de ocupação e manejo desordenado do solo têm sido as principais fontes de impactos e degradação dos ambientes ripários (TANIWAKI et al., 2017).

As matas ripárias constituem zonas denominadas Áreas de Preservação Permanente (APPs), cujos limites e extensão são definidos pela Lei de Proteção da Vegetação Nativa, entretanto, muitas vezes em áreas urbanas, tais limites são infringidos (MORAIS et al., 2017; BRASIL, 2012; GONÇALVES et al., 2005), o que contraria a própria legislação, uma vez que qualquer intervenção ou a supressão de vegetação nativa em APPs somente poderia ocorrer nas hipóteses de utilidade pública, de interesse social ou de baixo impacto, nos casos caracterizados na referida lei (BRASIL, 2012).

A aplicabilidade da preservação integral de APPs situadas próximas ou em áreas urbanas normalmente é dificultada, principalmente pela degradação e o impacto que elas sofrem, causados principalmente pela ação antrópica. A degradação dessas áreas ocorre de várias formas, por exemplo, através de deposição de resíduos, lançamento de efluentes e construções irregulares (LACORTE et al., 2015). Outros indicadores potenciais de degradação florestal incluem: incêndio, desmatamento, fragmentação, 
dominância de espécies exóticas ou invasoras (REDDY et al., 2016).

Diante disso, torna-se pertinente identificar e mensurar os principais impactos ambientais de natureza negativa (que causam danos à qualidade de um fator ou parâmetro ambiental) presentes em Áreas de Preservação Permanente urbanas, que deveriam estar conservadas e destinadas à preservação de suas funções ambientais.

Dentre as metodologias de diagnósticos ambientais existentes, a Avaliação de Impacto Ambiental (AIA) é uma importante ferramenta de diagnóstico, constituindo uma abordagem sistemática utilizada na identificação e avaliação de impactos benéficos e nocivos sobre os componentes físicos, biológicos e socioeconômicos do ambiente, que podem surgir a partir da implementação de projetos, planos, programas ou políticas públicas (SÁNCHEZ, 2006; GILBUENA JUNIOR et al., 2013).

Nessa perspectiva, o objetivo do presente estudo foi avaliar os principais impactos ambientais, de natureza negativa, existentes na área de APP do rio Paranaíba, no município de Patos de Minas e apontar inferências para mitigação dos impactos e recuperação ambiental das áreas degradadas.

\section{MATERIAIS E MÉTODOS}

\section{Área de estudo}

O presente estudo foi realizado na APP do rio Paranaíba. O trecho analisado possui $20,2 \mathrm{~km}$ de extensão e em sua maior parte está delimitando o perímetro urbano da sede de Patos de Minas - MG (Figura 1). Este trecho apresenta vários bairros consolidados, próximos a margem direita do rio, enquanto que a margem esquerda, faz limite com propriedades particulares da zona rural e com o distrito industrial III do município. Foram considerados para delimitação da APP, os parâmetros legais da Lei de proteção da Vegetação nativa, correspondente à faixa de 50 metros a partir da borda do leito regular.
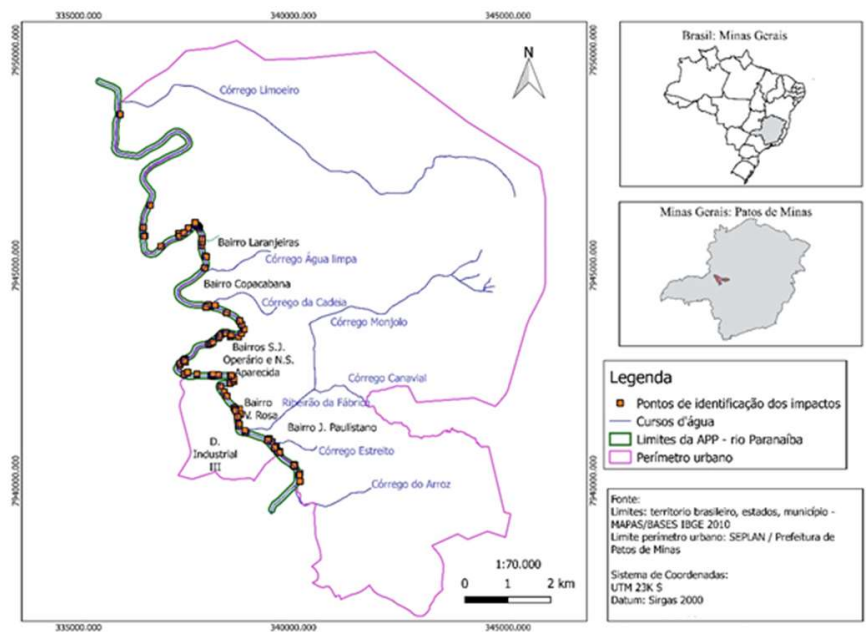

Figura 1: Área de Preservação Permanente (APP) do rio Paranaíba (presente estudo) no município de Patos de Minas e localização dos pontos visitados em campo ao longo da APP ( $N=107$ pontos) para identificação dos impactos ambientais.

\section{Identificação e avaliação de impactos ambientais}

Para esta análise, foram visitados 107 pontos na APP do rio Paranaíba, usando um GPS PRO XR L1/L2 
e câmera digital Sony W830, 20.1 mp, para o levantamento de impactos ambientais na APP considerada

(Figura 1). Em cada ponto visitado, foi verificada a presença / ausência dos seguintes impactos ambientais negativos, de origem antrópica: disposição de resíduos sólidos diversos (tais como plásticos, pneus, resíduos da construção civil e de demolição, latas de tintas, papéis, etc.), presença de bovinos/equinos na APP, presença de espécies exóticas e/ou invasoras, lançamento de efluentes (domésticos ou industriais), drenagens urbanas sem estruturas de dissipadores pluviais, erosão com assoreamento, trilhas internas na APP, desbastes, pescas e presença ou indícios de fogo. A identificação dos impactos ambientais baseou-se na literatura de Sánchez (2006) e interpretação dos impactos ambientais quanto sua importância e magnitude foi feita por meio da matriz de interação de impactos ambientais, adaptada de Leopold et al. (1971), considerando os conceitos de Almeida et al. (2008) e Bisset (1980). Os valores ponderados para os atributos dos impactos (Tabela 1) foram posteriormente utilizados para a determinação da magnitude e importância dos impactos ambientais na matriz adaptada de Leopold (1971).

Tabela 1: Atributos e valoração utilizados para determinação da magnitude e da importância dos impactos ambientais levantados na área de APP do rio Paranaíba (trecho urbano), em Patos de Minas - MG.

\begin{tabular}{|c|c|c|c|}
\hline \multirow{2}{*}{ Atributos } & \multicolumn{3}{|l|}{ Valor } \\
\hline & 1 & 2 & 3 \\
\hline Tipo de ação & $\begin{array}{l}\text { Enésima: relação enésima em } \\
\text { relação à ação. }\end{array}$ & $\begin{array}{l}\text { Secundária: quando faz parte de } \\
\text { uma reação secundária em relação } \\
\text { à ação, fazendo parte de uma } \\
\text { cadeia de reações. }\end{array}$ & $\begin{array}{l}\text { Primária (Direta): simples } \\
\text { reação de causa e efeito. }\end{array}$ \\
\hline $\begin{array}{l}\text { Ignição (tempo } \\
\text { para se } \\
\text { manifestar) }\end{array}$ & $\begin{array}{l}\text { Longo prazo: quando o efeito se } \\
\text { manifesta com uma longa } \\
\text { defasagem de tempo em relação à } \\
\text { ação. }\end{array}$ & $\begin{array}{l}\text { Médio prazo: quando o efeito se } \\
\text { manifesta com certa defasagem } \\
\text { de tempo em relação à ação }\end{array}$ & $\begin{array}{l}\text { Imediata: o efeito do impacto } \\
\text { surge simultaneamente com a } \\
\text { ocorrência da ação }\end{array}$ \\
\hline $\begin{array}{l}\text { Duração } \\
\text { (permanência) }\end{array}$ & $\begin{array}{l}\text { Curto prazo: os efeitos dos } \\
\text { impactos permanecem no } \\
\text { ambiente somente enquanto durar } \\
\text { a ação ou em no máximo } 1 \text { ano } \\
\text { após ocorrer a ação. }\end{array}$ & $\begin{array}{l}\text { Médio Prazo: os impactos ou seus } \\
\text { efeitos permanecem no ambiente } \\
\text { de } 1 \text { a } 10 \text { anos. }\end{array}$ & $\begin{array}{l}\text { Longo Prazo: os impactos ou } \\
\text { seus efeitos permanecem no } \\
\text { ambiente por tempo } \\
\text { desconhecido ou ilimitado, ou } \\
\text { ainda, superior a } 10 \text { anos. }\end{array}$ \\
\hline $\begin{array}{l}\text { Extensão } \\
\text { (Abrangência) }\end{array}$ & $\begin{array}{l}\text { Local: o alcance do impacto é no } \\
\text { próprio local da ação. }\end{array}$ & $\begin{array}{l}\text { Regional: quando a abrangência } \\
\text { ou consequência do impacto se } \\
\text { estende a uma região além do } \\
\text { local onde houve a ação. }\end{array}$ & $\begin{array}{l}\text { Global: impacto que pode ter } \\
\text { abrangência ou consequência } \\
\text { global. }\end{array}$ \\
\hline Reversibilidade & $\begin{array}{l}\text { Reversível: quando cessada a ação } \\
\text { causadora, as condições ambientais } \\
\text { originais são totalmente } \\
\text { restabelecidas }\end{array}$ & $\begin{array}{l}\text { Reversível parcialmente: quando } \\
\text { cessada a ação causadora, as } \\
\text { condições ambientais originais são } \\
\text { parcialmente restabelecidas }\end{array}$ & $\begin{array}{l}\text { Irreversível: mesmo após } \\
\text { cessada a ação causadora, o } \\
\text { componente ambiental } \\
\text { afetado não retorna para as } \\
\text { condições originais, pelo } \\
\text { menos em um horizonte de } \\
\text { tempo aceitável pelo homem }\end{array}$ \\
\hline $\begin{array}{l}\text { Intensidade } \\
\text { (Quantificação } \\
\text { da ação } \\
\text { impactante) }\end{array}$ & $\begin{array}{l}\text { Baixa: baixo nível de alteração da } \\
\text { característica/componente } \\
\text { ambiental; baixo grau de } \\
\text { modificação. }\end{array}$ & $\begin{array}{l}\text { Média: nível médio de alteração } \\
\text { da característica/componente } \\
\text { ambiental; baixo grau de } \\
\text { modificação. }\end{array}$ & $\begin{array}{l}\text { Alta: alto grau de modificação } \\
\text { do componente ambiental; } \\
\text { efeito devastador. }\end{array}$ \\
\hline
\end{tabular}

Fonte: Almeida et al. (2008), adaptada.

No eixo horizontal da matriz, foram dispostos os impactos observados na APP e em seu eixo vertical, os componentes ambientais sobre os quais esses impactos interferem, sendo eles: meio físico, meio biótico e meio antrópico. A magnitude $(\mathrm{m})$ é definida como a medida de gravidade da alteração do valor de um parâmetro ambiental (ALMEIDA et al., 2008; BISSET, 1980), sendo mensurada pela soma dos valores determinados para os atributos: extensão (E), permanência / duração (D) e intensidade (I), de acordo com a 
equação: $m=E+D+I$. A escala de valores, resultante da análise dos atributos citados foi baseada em Almeida et al. (2008) e Leopod et al. (1971) - baixo: (3) e (4) / médio: (5) e (6) / alto (7), (8) e (9).

A importância do impacto (I), corresponde segundo BISSET (1980), à medida da significância do mesmo e foi calculada com base na adaptação da fase matricial de Almeida et al. (2008) a partir da matriz de Leopold et al. (1971), sendo o resultado da soma dos valores de magnitude $(\mathrm{m})$ somada aos atributos: tipo de ação $(A)$, ignição $(\lg )$ e reversibilidade $(\mathrm{R})$, conforme a equação: $i=m+A+\lg +R$. Sua escala, adaptada para o presente estudo contém os respectivos valores: baixo: (6), (7), (8), (9) e (10) / médio: (11), (12) e (13) / alto: (14), (15), (16), (17) e (18).

A partir da valoração da magnitude e da importância dos impactos ambientais, que, de acordo com Leopold et al. (1971) são os atributos principais a serem avaliados e que devem ser considerados na análise final, foi montada uma matriz final e sintetizada com os valores atribuídos a cada fator impactante.

\section{RESULTADOS E DISCUSSÃO}

\section{Impactos ambientais observados na APP do Rio Paranaíba}

Dentre os impactos observados na APP, a erosão/assoreamento, a introdução de espécies Exóticas, a disposição de Resíduos sólidos e o lançamento de Esgoto apresentaram a maior frequência (Figura 2). Da totalidade, estes quatro impactos somam $62 \%$ da frequência observada nos pontos.

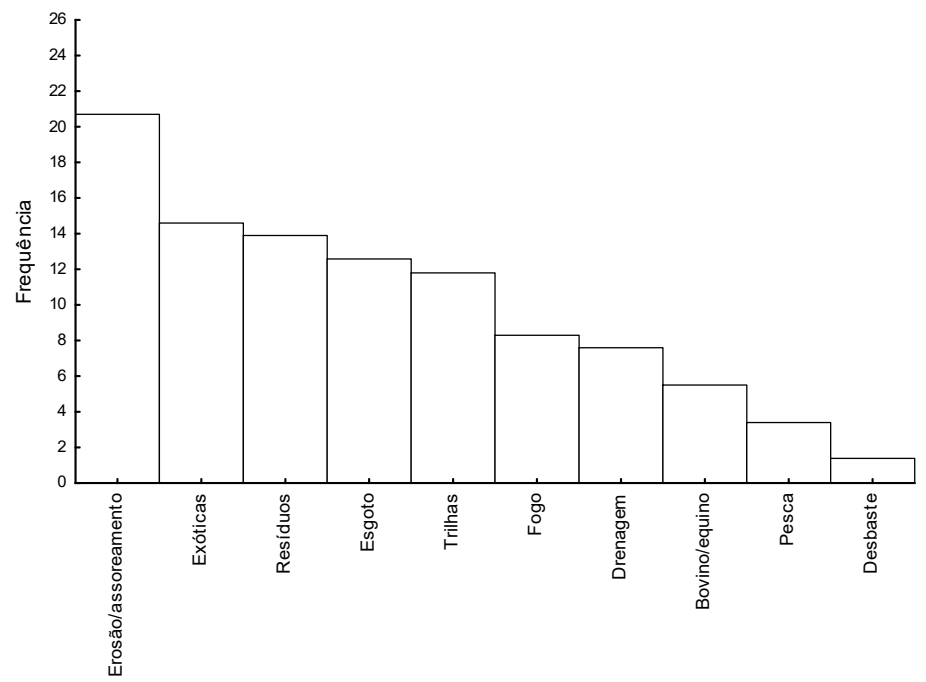

Figura 2: Distribuição da frequência dos impactos ambientais observados ( $N=107$ pontos) ao longo da APP do rio Paranaíba, perímetro urbano, Patos de Minas, MG.

A matriz adaptada de Leopold (Tabela 2) contém a análise final dos fatores mais impactantes encontrados na APP considerando a magnitude e a importância dos impactos aos meios físico, biótico e antrópico. Os fatores que mais impactaram o meio físico, considerando apresentarem alta magnitude e alta importância para todos os parâmetros deste meio foram: a disposição de resíduos sólidos e o desbaste.

Merecem destaque também os impactos relacionados ao lançamento de esgoto, presença de animais (bovinos/equinos) na APP e a falta/ineficiência de dissipadores hidráulicos nos finais das redes de drenagem urbana, que podem apresentar efeitos com alta magnitude e alta importância em três dos cinco 
parâmetros analisados para o meio físico (Tabela 2), por alterarem características do solo e da água.

Tabela 2: Matriz dos impactos ambientais identificados ao longo da APP do rio Paranaíba, perímetro urbano, avaliados quanto aos atributos: magnitude e importância.

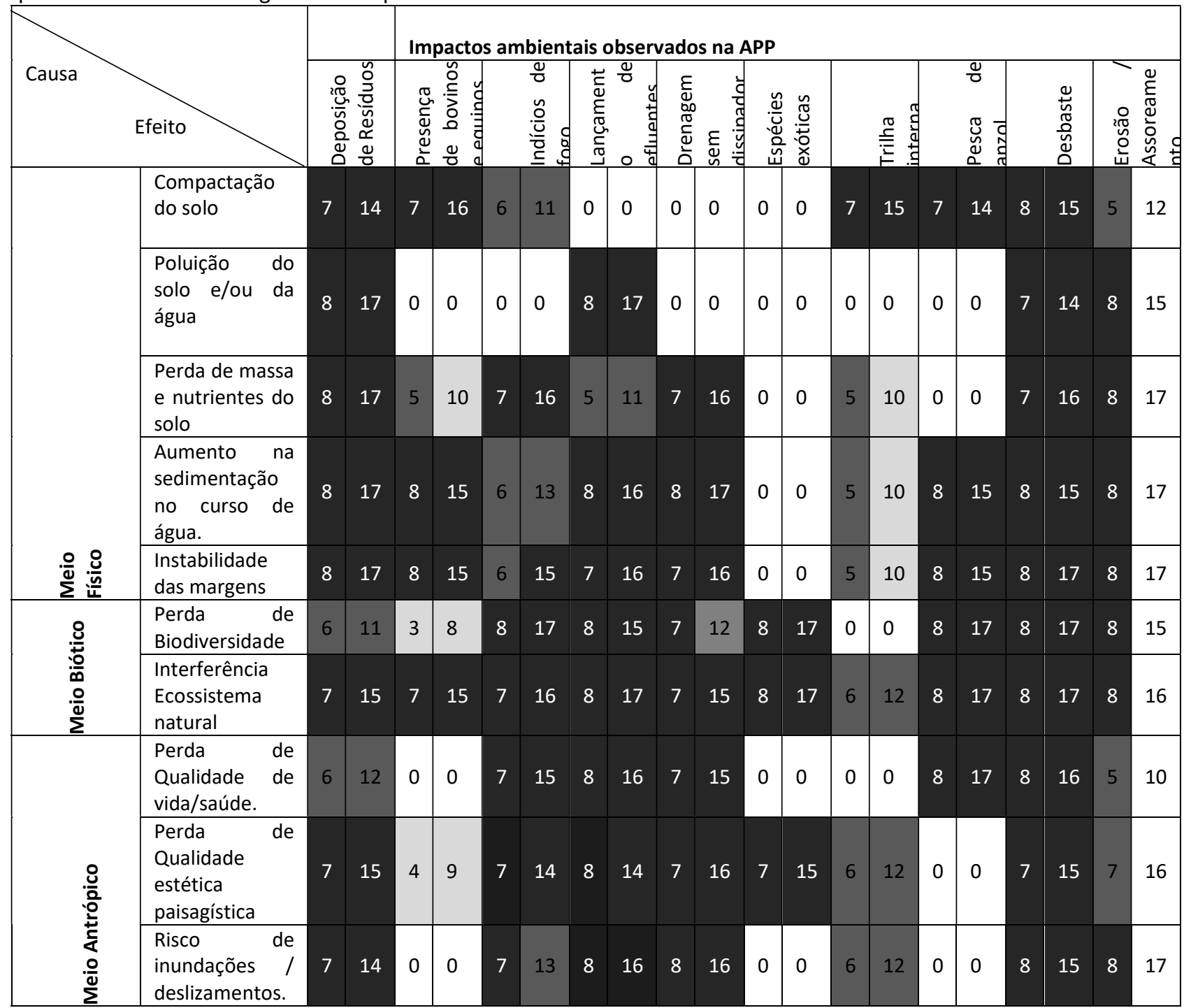

Legenda: 0: impacto neutro. Para magnitude (m): Alto: (7), (8) e (9) / Médio: (5) e (6) / Baixo: (3) e (4). Para importância (i): Alta: (14), (15), (16), (17) e (18) / Média: (11), (12) e (13) / Baixa: (6), (7), (8), (9) e (10). Disposição na quadrícula dos pesos referentes aos atributos $(\mathrm{m})$ e $(\mathrm{i})$ dos impactos:

$$
\begin{aligned}
& \mathrm{m}=\mathrm{E}+\mathrm{D}+\mathrm{I} \\
& \mathrm{i}=\mathrm{m}+\mathrm{A}+\mathrm{Ig}+\mathrm{R} .
\end{aligned}
$$

\section{Alto}

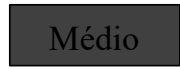

Baixo

Neutro

\begin{tabular}{|l|l|}
\hline $\mathrm{m}$ & $\mathrm{i}$ \\
\hline
\end{tabular}

A presença de resíduos detectados ao longo da APP ocorreu tanto de forma dispersa, quanto concentrada. Dentre estes resíduos, alguns possuem um longo tempo de permanência no ambiente, como é o caso dos plásticos, pneus e vidros; outros com alto potencial de contaminação, por exemplo latas com restos de tintas e ainda outros com alto potencial de movimento de massa, como é o caso de resíduos da construção civil e de demolição. Diante da variedade de resíduos encontrados, da alta frequência dentre os impactos observados na APP (Figura 2) e considerando o potencial de carreamento deles pelas águas de chuva, evidenciado pela presença de resíduos sólidos nos pontos de assoreamento do rio, a valoração dos atributos magnitude e importância foi alta para os parâmetros avaliados do meio físico. A presença de resíduos em APP foi frequente devido proximidade da APP com bairros e a falta de isolamento das áreas de 
proteção ambiental.

Larocca et al. (2017) também analisou impactos ambientais, a partir do meio geofísico, biológico e antrópico, ocorrentes em uma área de APP localizada na cidade de Londrina/PR, por meio de uma matriz derivada de Leopold, onde destacou que um dos principais impactos negativos acarretados no objeto de seu estudo, foi o carregamento de resíduos para o corpo hídrico, principalmente pela proximidade com um bairro e por existir diversos terrenos em construção ao redor.

Os sinais de desbastes recentes verificados na APP foram pontuais, em pontos situados próximos ao bairro Nossa Senhora Aparecida, onde existem também construções irregulares sendo visível o risco de deslizamento. A presença de vegetação ciliar margeando os corpos d'água é de grande importância para a manutenção dos sedimentos das margens, contribuindo para redução da erosão e assoreamento, além de dificultar a entrada de resíduos sólidos no leito do rio, os quais são carregados após chuvas intensas (MAGALHÃES et al., 2013). Assim, o desbaste, mesmo que pontual em APP, é um fator altamente impactante ao meio físico, com valoração alta de magnitude e intensidade nos meios físico, biótico e antrópico (Tabela 2), sendo necessário a aplicação de medidas de fiscalização ambiental destas áreas, conscientização da população próxima, além de reposição com espécies nativas no local de desbaste.

Apesar de ser o manancial de abastecimento humano da cidade, o rio Paranaíba encontra-se bastante poluído, conforme verificado visualmente em campo e conforme aponta o relatório de monitoramento do Instituto Mineiro de Gestão das Águas, que mostra que ao longo dos últimos anos, o rio Paranaíba vem apresentando IQA ruim perto de centros urbanos e cita a jusante da cidade de Patos de Minas com alguns indicadores de IQA acima dos níveis estabelecidos pela legislação para corpos de água de Classe 2, que é o enquadramento do rio em questão (IGAM, 2015).

Neste sentido, segundo Pereira et al. (2016), os efluentes sem tratamento, podem alterar parâmetros físicos e químicos da água, como o pH natural e a concentração de oxigênio, aumentando a turbidez da água por meio da incorporação de carga orgânica, e injetando substâncias químicas diversas, o que afeta os padrões legais estabelecidos para qualidade das águas. Para minimizar esse problema, o tratamento integral dos efluentes de origem doméstica e industrial é fundamental.

A presença de bovinos e de equinos em APP foi um fator com alto grau de impacto ambiental para o meio físico, verificado pela valoração dos atributos para aspectos ambientais como compactação do solo, aumento da instabilidade das margens e ainda da sedimentação no curso de água. Assim, faz-se necessário o isolamento com cerca tipo alambrado das áreas de APP para impedir o trânsito de animais, conforme ressalta Durigan et al. (2010), e devem os bebedouros, preferencialmente, serem instalados nas pastagens ou podem ser delimitados corredores cercados, para que o gado possa beber água no rio, mas em ponto específico.

A ausência ou ineficiência de dissipadores nos lançamentos finais de drenagem urbana na APP podem causar efeitos impactantes de alta magnitude e importância ao solo e a água, como instabilidade das margens, perda de massa e nutrientes do solo (Tabela 2). De acordo com Pereira et al. (2018), a infraestrutura de drenagem e dissipação de águas pluviais no corpo hídrico devem ser suficientes para conduzir os 
escoamentos permitindo retardamento da velocidade da água em parte do volume precipitado, visando proteger as áreas de fundo de vale nas cidades.

Como forma de minimizar os efeitos de degradação decorrentes da ausência ou ineficiência de dissipadores finais de água nas APPs, os órgãos ambientais reguladores devem exigir dos empreendedores de loteamento, e do poder público a execução de medidas mitigadoras e compensatórias como, por exemplo, reflorestamento e execução de técnicas de conservação e recuperação do solo. De acordo com a Tabela 2, o meio biótico foi afetado pelos efeitos dos fatores impactantes observados ao longo da APP do rio Paranaíba. Nesse sentido, destacam-se os indícios e presença de fogo, presença de espécies exóticas, desbastes, o lançamento de efluentes e as ocorrências de pesca. Todos esses fatores apresentaram alta magnitude e importância para os atributos: perda de biodiversidade e interferência no ecossistema natural.

As ocorrências de princípios de incêndio antrópico na APP podem ter sido facilitadas pela existência de trilhas e acessos internos, que facilitam o fluxo no interior da área e também a falta de isolamento e proteção. De acordo com Melo et al. (2010), os principais efeitos do fogo sobre os ambientes florestais são perdas nos estoques de biomassa, alterações no ciclo hidrológico e de nutrientes e a perda de biodiversidade, o que pode estar associado a invasões biológicas. Além disso, se a queima ocorre no ápice da estação seca, a matéria orgânica do subsolo pode queimar durante vários dias, esterilizando o solo (PEREIRA et al., 2016).

Além das gramíneas Urochloa spp. (braquiárias), Panicum maximum Hochst. ex A. Rich. (capimcolonião) e Melinis minutiflora P. Beauv. (capim-gordura), foram identificadas na área outras espécies exóticas e invasoras, como: Ricinus communis L. (mamona), Leucaena leucocephala (Lam.) de Wit. (leucena), Guadua paraguayana Döll (bambu) e Eucalyptus spp. (eucaliptos). A presença de pelo menos uma dessas espécies na APP teve alta frequência (Figura 2) em relação ao número total de ocorrências de impactos ambientais verificados na área.

Dentre os métodos de controle de gramíneas e de outras espécies invasoras relatados na literatura estão a cobertura com lona plástica, corte raso da biomassa, uso de leguminosas forrageiras (NASCIMENTO, 2014) e abertura de clareiras ao redor de plântulas (MARTINS, 2014). Porém, devido à permanência no banco de sementes durante anos (MORAIS et al., 2017), a eliminação definitiva de espécies invasoras é dificultada, comprometendo as medidas de controle. Dessa forma, o monitoramento e prevenção em ecossistemas frágeis como as APPs é fundamental.

O lançamento de efluentes sem tratamento, por meio de desembocaduras de afluentes ou de tubulações, foi detectado em vários pontos visitados, com situação crítica na foz dos córregos urbanos no rio Paranaíba. À jusante de alguns desses pontos, foi presenciada também a mortalidade de peixes. A elevada carga orgânica advinda do esgoto sem tratamento, somadas à menor vazão de água decorrente do período seco, e, ainda, a deposição de sedimentos provenientes de processos erosivos podem ter diminuído a disponibilidade de oxigênio na água, afetando a fauna aquática. Assim, este fator apresenta alto grau de impacto ao meio biótico, conforme mostrado na matriz de impactos (Tabela 2).

Em relação ao meio antrópico, os impactos que apresentaram maior relevância em função da alta magnitude e alta importância para todos os atributos analisados para este meio foram: o lançamento de 
efluentes, ausência de dissipador final eficiente de drenagem urbana e o desbaste, com valoração alta tanto para magnitude quanto para a importância do impacto, considerando os aspectos:perda da qualidade de vida/saúde, perda da qualidade estética paisagística e risco de inundações ou deslizamentos.

O rio Paranaíba e alguns de seus afluentes urbanos possuem históricos de inundações, conforme dados de Nogueira (2017), que afirmam que essas inundações se estendem para além dos 50 metros de APP alcançando a cota de 782 metros, que é definida como a cota limite de inundação/segurança.

No que diz respeito aos impactos com efeitos no meio antrópico, as inundações e deslizamentos em geral, combinam condições ambientais (topografia, cobertura vegetal e clima, por exemplo) e socioeconômicas (densidade populacional, situação das moradias, renda, acesso à serviços de educação e saúde). Nesse processo, os grupos populacionais e os espaços geográficos mais vulneráveis são os mais fortemente afetados (FREIRE et al., 2014).

\section{Inferências e sugestões para mitigação dos impactos ambientais negativos na APP}

Para estas regiões, é necessário um maior planejamento urbano e investimentos por parte do poder público municipal, como forma de minimizar os impactos socioeconômicos, como por exemplo a implantação de parques lineares, reflorestamento e isolamento das áreas íngremes e retirada da população das áreas de risco aliada à programas habitacionais para alocação dessas pessoas em situação de vulnerabilidade socioambiental. Na Figura 3, é apresentada uma área onde foi identificado o risco de deslizamentos, com presença de moradias de pessoas com baixa renda na APP e ainda existência de uma via pública a menos de cinco metros da calha do rio, onde também foram observados muitos dos impactos que foram analisados neste estudo. Esta região fica próxima ao Bairro Nossa Senhora Aparecida (Figura 3-A). Na Figura 3-B é possível observar uma região crítica de degradação ambiental, na região da confluência do córrego da Cadeia com o rio Paranaíba, resultante dos impactos ambientais observados na APP. Neste ponto, observou-se drenagem sem dissipador, erosão, assoreamento, presença de resíduos, efluentes e espécies exóticas/invasoras, além de pastagem onde deveria estar a mata ciliar.

A APP do rio Paranaíba, na confluência do córrego da Cadeia, constitui uma das situações críticas de degradação ambiental, evidenciada pela falta de vegetação nativa nas margens, presença de solo exposto com erosões e assoreamento no leito. A alta velocidade da água que chega, principalmente em eventos torrenciais mais severos, agravados pela ineficiência da drenagem pluvial urbana pode ter ocasionado escavação de material próximo a foz, causando instabilidade dos taludes fluviais e degradação ambiental.

A restauração florestal em áreas de intensa erosão deve envolver técnicas de bioengenharia a fim de conter os processos erosivos (sulcos e voçorocas). Posteriormente, deve-se usar topsoil associado com o plantio de mudas já estabelecidas (maior porte), visando agregar biomassa viva e competir com as gramíneas invasoras. Após a mitigação dos principais impactos e fatores de degradação, cercamento e realização de processos físicos, associados aos processos vegetativos, pode-se efetuar o enriquecimento das áreas com pouca cobertura arbórea, usando espécies nativas de vegetação ripária.

Conforme Durlo et al. (2005), para estabilização e contenção de taludes fluviais, em processos 
erosivos avançados, deve-se aplicar técnicas de bioengenharia que envolvam dois tipos de ações indissociáveis e complementares: uma intervenção física e um tratamento vegetativo. A intervenção física consiste na retirada do material sedimentar, troncos, galhos, resíduos que obstruem o canal de drenagem regular do rio, com posterior reconstrução da margem. Essa remodelagem é apoiada pela construção de um anteparo de pedras e madeira junto ao nível normal da água, com vistas a ancorar o pé do talude, proporcionando maior estabilidade e proteção, de modo que a mesma possa receber o tratamento vegetativo. Nessas áreas, o simples cercamento e isolamento juntamente com plantio de mudas, podem não ser suficientes para a recuperação ambiental. Desta forma as estratégias devem encorajar a integração e o aprendizado recíproco no processo de planejamento, design e gestão, assim com as particularidades de cada cidade (SALBITANO et al., 2016).
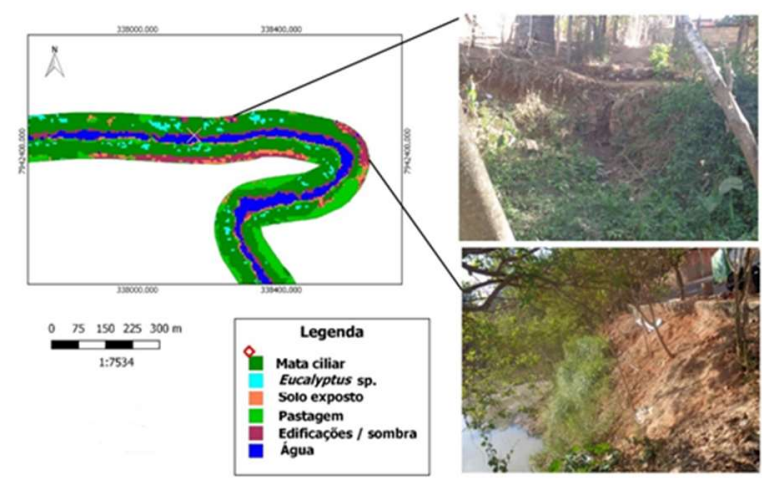

A)
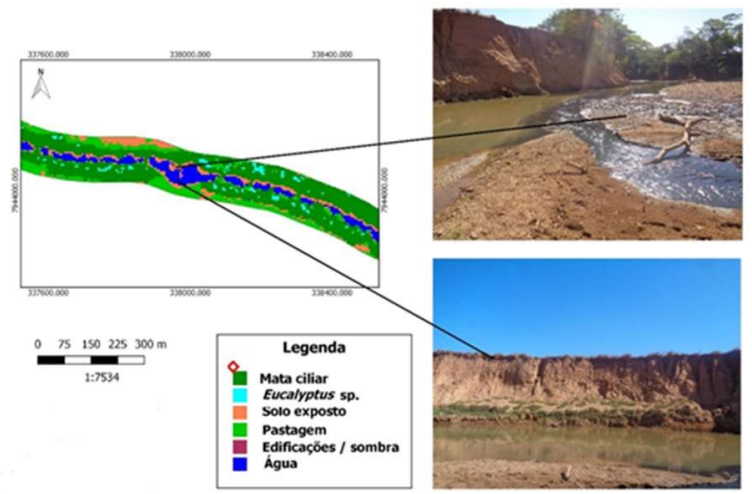

B)

Figura 3: Áreas críticas de degradação ambiental dentro da área de APP e leito do rio Paranaíba . (A) - APP, Patos de Minas/MG, com presença de rua e moradias, esgoto, desbaste, lixo, erosão/assoreamento e espécies exóticas. (B) local do rio Paranaíba onde deságua o Córrego da Cadeia, em Patos de Minas/MG, onde verificou-se presença de erosão, assoreamento, esgoto, lixo e espécies exóticas. Imagens da APP obtidas por classificação pela Máxima Verossimilhança, satélite Rapideye (2014).

A Figura 4 ilustra outros dois pontos críticos de degradação ambiental em função dos impactos ambientais negativos registrados nas áreas. Estes locais ficam próximos ao Bairro Laranjeiras. Na Figura 4-A verificou-se degradação ambiental evidenciada pelo solo exposto, erosão das margens e assoreamento, presença de esgoto, indícios de fogo, lixo e espécies exóticas. Em 4-B observa-se o ponto de confluência do córrego Água Limpa com o rio Paranaíba, londe verificou-se a presença de esgoto, lixo, indícios de fogo, espécies exóticas e erosão e assoreamento, fezes de bovinos, o que indica presença de animais na área.

O uso de telas vegetais ou similares, que são produtos fabricados por empresas especializadas, quando aplicadas sobre substratos em taludes também favorecem o desenvolvimento da vegetação em áreas degradadas. São fixadas no solo através de grampos de ferro não galvazinados ou estacas de madeiras. Este material aumenta a infiltração, protege fisicamente o substrato abaixo e mantém a umidade e temperatura (TORRES et al., 2008). Ainda conforme esses autores podem ser plantadas espécies forrageiras como leguminosas, como forma de cobertura do solo, tais como: Cajanus cajani (L.) Millsp. (feijão-gandu) ou gramíneas nativas como Paspalum atratum Swallen (capim-pojuca). 

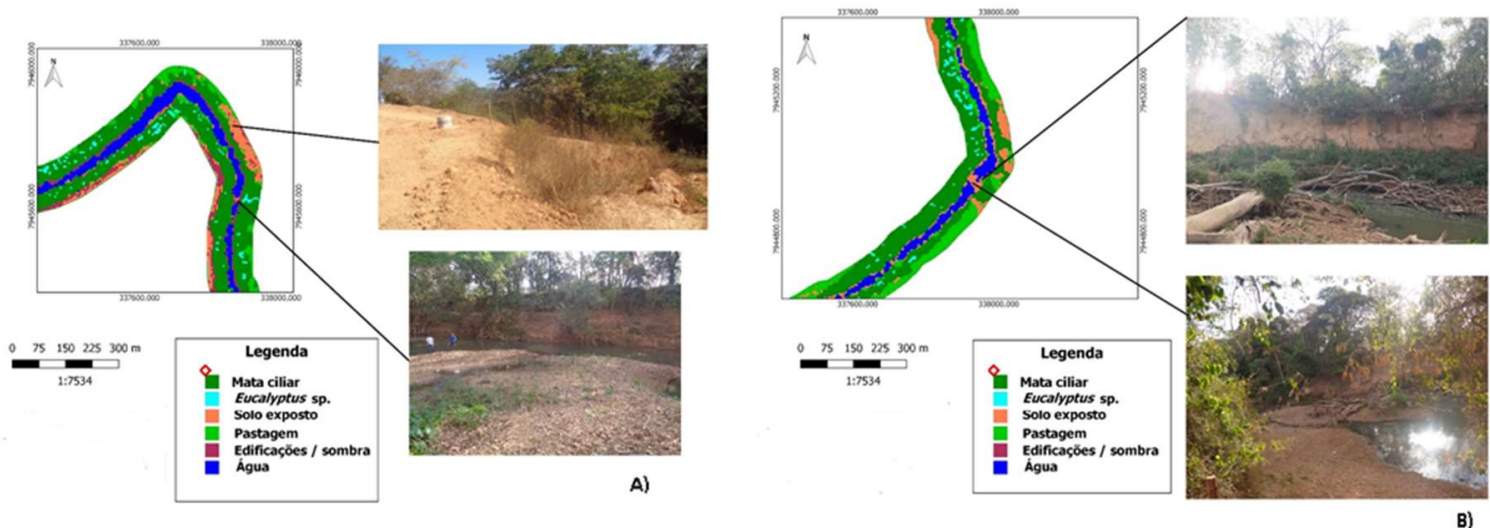

Figura 4: Área crítica de degradação ambiental dentro da área de APP e leito do rio Paranaíba, Patos de Minas/MG, onde verificou-se presença de solo exposto, erosão, assoreamento, esgoto, indícios de fogo, lixo e espécies exóticas (A), e na confluência do córrego Água limpa (B) houve presença de impactos semelhantes, sendo também notada a presença de animais na APP. Imagens da APP obtidas por classificação pela Máxima Verossimilhnaça, satélite Rapideye (2014)

Para voçorocas (estágio avançado de erosão caracterizado por abertura de sulcos profundos), também podem ser colocadas paliçadas com material de baixo custo como bambus, pedras e sacos de ráfia, com a finalidade de conter sedimentos dentro da própria erosão, consorciado com instalação de canaletas nas paredes laterais e no leito da voçoroca, de maneira que a paliçada fique bem encaixada, sem deixar brechas para a passagem de água (TORRES et al., 2008).

É importante ressaltar que aliadas às práticas corretivas de recuperação de erosão e assoreamento dessas áreas, se fazem também necessárias as medidas preventivas, como por exemplo a melhoria do sistema de macro e micro drenagem urbana, conforme já apontado pelo Estudo de concepção de gestão das águas pluviais da drenagem urbana de Patos de Minas (PATOS DE MINAS, 2014), ainda são necessários reparos urgentes e manutenções em dispositivos desses sistemas, tais como os dissipadores finais, conforme detectado no presente estudo. Ações de educação ambiental e de fiscalização no sentido de coibir os depósitos irregulares de resíduos, em vias públicas ou em áreas de APP e entorno, também são importantes, uma vez que tais resíduos em incidência nas águas pluviais podem comprometer a drenagem e ainda se depositar em leitos de mananciais favorecendo inundações.

Após a mitigação dos principais distúrbios e fatores de degradação, cercamento, e realização de estratégias físicas, e de tratamentos vegetativos de forração nos pontos mais críticos mostrados, podem ser realizados plantios de mudas de espécies arbóreas, apropriadas para zonas ripárias. Modelos e grupos de espécies podem ser utilizados com base em Durigan et al. (2010) e Martins (2014).

O plantio deve ser realizado no início da estação chuvosa para que as mudas tenham umidade suficiente para seu estabelecimento inicial. Também é necessário anteriormente ao plantio o controle de formigas cortadeiras na área, preparação de substrato, abertura das covas manualmente com auxílio de enxadão ou escavadeira ("mão-de-vaca"), ou ainda perfuradora mecanizada tipo manual, sendo o dimensionamento recomendado de $0,40 \times 0,40 \times 0,40 \mathrm{~cm}$ para solos muito compactados e de $0,30 \times 0,30 \times$ 0,30 cm para solos não compactados, de acordo com Martins (2014).

Ainda de acordo com Martins (2014) em recuperação de áreas de APP, não se utilizam calcário e 
fertilizantes químicos, buscando um comportamento das mudas semelhante ao observado em condições de regeneração natural. Entretanto, dadas as condições de degradação, perdas e empobrecimento de solo, fazse necessário esses procedimentos, desde que previamente sejam feitas análises físico-químicas do solo, como indicativo dessa necessidade.

Conforme relatado por Sampaio et al. (2007), o pisoteio de animais em áreas florestais, interfere nos processos sucessionais e de regeneração devido à quebra ou herbivoria de plântulas e compactação do solo. Sendo assim, em áreas de pastagens, deve-se incluir além de técnicas de controle de gramíneas, a descompactação do solo, que muitas vezes se faz necessária. De acordo com Torres et al. (2008), solos compactados têm baixa capacidade de infiltração e distribuição de água e menor porosidade, impedindo a ação capilar da água e, dessa forma, ocasionando um aumento da erosão laminar superficial, reduzindo a atividade microbiana e prejudicando o desenvolvimento de raízes de plantas. Porém, em áreas de APP, onde o revolvimento do solo deve ser restrito ao mínimo indispensável, para evitar ou agravar problemas de erosão, as operações de limpeza, revolvimento e plantio devem ser manuais (DURIGAN et al., 2010).

\section{CONCLUSÕES}

Os impactos de maior frequência foram erosão/assoreamento, presença de espécies exóticas/invasoras e lançamento de efluentes e resíduos sólidos. A maior parte dos impactos identificados apresentaram alta magnitude e importância nos meios físico, biótico e antrópico, conforme a análise de seus atributos na matriz adaptada de Leopold. A avaliação desses impactos em conjunto com a elaboração da Matriz usando magnitude e importância no interior da APP, possibilitou diagnosticar áreas críticas de degradação e que são prioritárias para recuperação na área.

Apesar da reconhecida importância das zonas ripárias, neste estudo foi diagnosticado que elas estão altamente impactadas e degradadas em ambiente urbano. Os resultados gerados, bem como as diretrizes ambientais para recuperação aqui discutidas, indicaram as potencialidades e necessidades de recuperação ambiental da APP do trecho urbano do rio Paranaíba, em Patos de Minas, oferecendo subsídios para uma gestão ambiental mais efetiva de zonas ripárias inseridas na matriz urbana.

\section{REFERÊNCIAS}

ALMEIDA, J. R.. Ciências Ambientais. 2 ed. Rio de Janeiro: Thex, 2008.

BISSET, R.. Métodos para avaliação de impacto ambiental: uma mostra seletiva. (PACD environmental impacts assessment and planing Unit). In: SEMINÁRIO TÉCNICO DE AIA. Anais. Rio de Janeiro: FEEMA, 1986

BRASIL. Lei $\mathbf{n} . \mathbf{1 2 . 6 5 1}$ de $\mathbf{2 5}$ de maio de 2012. Código Florestal Brasileiro. Brasília: DOU, 2012.

DURLO, M. A.; SUTILI, F. J.. Bioengenharia: manejo biotécnico de cursos de água. Porto Alegre: EST, 2005.

DURIGAN, G.; MELO, A. C. G.; MAX, J. C. M.; BOAS, O. V.; CONTIÉRI, W. A.; RAMOS, V. S.. Manual para a recuperação das matas ciliares do oeste paulista. 4 ed. Assis: Instituto
Florestal - Secretaria de Meio Ambiente: Triunfal, 2010.

FREIRE, N. C. F.; BONFIM, C. V.; NATENZON, C. E.. Vulnerabilidade socioambiental, inundações e repercussões na Saúde em regiões periféricas: o caso de Alagoas, Brasil. Ciência e Saúde Coletiva, v.19, n.9, p.3755-3762, 2014. DOI: http://doi.org/10.1590/1413-81232014199.07572014

GILBUENA JUNIOR, R.; KAWAMURA, A.; MEDINA, R.; AMAGUCHI, H.; NAKAGAWA, B. D. D.. Environmental impact assessment of structural flood mitigation measures by a rapid impact assessment matrix (RIAM) technique: A case study in Metro Manila, Philippines. Science of the Total Environment, v.456-457, p.137-147, 2013. DOI: http://doi.org/10.1016/i.scitotenv.2013.03.063

GONÇALVES, R. M. G.; GIANNOTTI, E.; GIANNOTTI, J. D. G.; 
SILVA, A.. Aplicação do modelo de revegetação em áreas degradadas, visando à restauração ecológica da microbacia do córrego da fazenda Itaqui, no município de Santa Gertrudes, SP. Revista do Instituto Florestal, v.17, p.73-95, 2005. DOI: http://doi.org/10.5935/ietia.v7i28.714

IGAM. Instituto Mineiro de Gestão das Águas. Relatório anual de gestão e situação dos recursos hídricos de Minas Gerais -2014. Belo Horizonte: IGAM, 2015.

LACORTE, I. M.; ALMEIDA, M. R. R.. Impactos ambientais em Áreas de Preservação Permanente de centros urbanos: o caso da Bacia do Córrego Liso em Uberlândia. Enciclopédia Biosfera, v.11, n.22, p.464-1475, 2015. DOI: http://doi.org/10.18677/Enciclopedia Biosfera 2015175

LAROCCA, A. G.; CARDOSO, C.; ANGELIS, B. L. D.. O impacto da ocupação de fundo de vales em áreas urbanas: estudo de caso do Lago Igapó em Londrina - PR. Revista Nacional de Gerenciamento de Cidades, v.5, n.30, p.52-64, 2017. DOI: http://dx.doi.org/10.17271/2318847253020171539

LEOPOLD, L. B.; CLARKE, F. E.; HANSHAW, B. B.; BALSLEY, J. R.. A Procedure for Evaluating Environmental Impact. Geological Survey Circular 645. Washington: USGS, 1971.

MARTINS, S. V.. Restauração florestal em áreas de preservação permanente e reserva legal. Viçosa: Centro de Produções Técnicas, 2014.

MAGALHÃES, S. E. F.; PIMENTEL, R. M. M.. Matas Ciliares: Análise Histórica dos Estudos Relacionados ao Tema. Revista Brasileira de Geografia Física, v.6, n.1, p.049-057, 2013. DOI: http://doi.org/10.26848/rbgf.v06.1.p049-057

MELO, A. C. G.; DURIGAN, G.. Impacto do fogo e dinâmica da regeneração da comunidade vegetal em borda de Floresta Estacional Semidecidual (Gália, SP, Brasil). Revista Brasileira de Botânica, v.33, n.1, p.37-50, 2010. DOI: http://doi.org/10.1590/S0100-84042010000100005

MORAIS, I. L.; SOARES, D. M.; NASCIMENTO, A. R. T.. As áreas úmidas no contexto do Código Florestal e a invasão biológica em veredas. In: SANTOS, F. R.. Contextualizando o Cerrado Goiano: entre questões socioeconômicas e socioespaciais e questões socioeducacionais e socioambientais. Curitiba: CRV, 2017. p.59-86.

NASCIMENTO, E. M.. Análise florístico-estrutural, controle de gramíneas invasoras e estímulo da regeneração natural em pastagens abandonadas. Dissertação (Mestrado em Ecologia e Conservação de Recursos Naturais) -Universidade Federal de Uberlândia, Uberlândia, 2014.

NOGUEIRA, T. P. N.. Mapeamento da susceptibilidade à inundação na bacia hidrográfica do ribeirão da Fábrica, município de Patos de Minas - MG. Dissertação (Mestrado em Qualidade Ambiental) - Universidade Federal de Uberlândia, Uberlândia, 2017.

ONO, S.. Sistema de suporte a decisão para gestão de água urbana - URBSSD. Dissertação (Mestrado em Engenharia) Universidade de São Paulo, São Paulo, 2008.
PATOS DE MINAS. Prefeitura Municipal. Manejo de águas pluviais de drenagem urbana do município de Patos de Minas MG: estudo de concepção de gestão das águas pluviais, Arquivo público, Patos de Minas, 2014.

PEREIRA, B. W. F.; MACIEL, M. N. M.; OLIVEIRA, F. A.; ALVES M. A. M. S.; RIBEIRO, A. M.; FERREIRA, B. M.; RIBEIRO, E. G. $P$.. Uso da terra e degradação na qualidade da água na bacia hidrográfica do rio Peixe-Boi, PA, Brasil. Revista Ambiente e Água, v.11, n.2, p.472-485, 2016. DOI:

http://doi.org/10.4136/ambi-agua.1802

PEREIRA, P. P.; PAREDES, E. A.; OKAWA, C. M.. Diagnóstico preliminar da integridade ambiental de fundos de vale. Engenharia Sanitária Ambiental, v.23, n.4, p.739-749, 2018. DOI: http://doi.org/10.1590/S1413-41522018169928

REDDY, C. S.; MANASWINI, G.; SATISH, K. V.; SINGH, S.; JHA, C. S.; DADHWAL, V. K.. Conservation priorities of forest ecosystems: Evaluation of deforestation and degradation hotspots using geospatial techniques. Ecological Engineering, v.91, n.1, p.333-342, 2016. DOI: http://doi.org/10.1016/j.catena.2007.03.009

SALBITANO, F.; BORELLI, S.; CONIGLIARO, M.; CHEN, Y. Guidelines on urban and peri-urban forestry. FAO Forestry Paper, n.178. Rome: Food and Agriculture Organization of the United Nations, 2016.

SAMPAIO, M. B.; GUARINO, E. S. G.. Efeitos do pastoreio de bovinos na estrutura populacional de plantas em fragmentos de floresta ombrófila mista. Revista Árvore, v.31, n.6, p.1035-1046, 2007. DOI: http://doi.org/10.1590/s0100$\underline{67622007000600008}$

SÁNCHEZ, L. E.. Avaliação de impacto ambiental: conceitos e métodos. São Paulo: Oficinas de Textos, 2006.

STUTTER, M.; BAGGALEY, N.; Ó HUALLACHÁIN, D.; WANG, C.. The utility of spatial data to delineate river riparian functions and management zones: A review. Science of the Total Environment, v.757, n.143982, 2021. DOI: http://doi.org/10.1016/j.scitotenv.2020.143982

TANIWAKI, R. H.; CASSIANO, C. C.; FILOSO, S.; FERRAZ, S. F. B.; CAMARGO, P. B.; MARTINELLI, L. A.. Impacts of converting low-intensity pastureland to high-intensity bioenergy cropland on the water quality of tropical streams in Brazil. Science of the Total Environment, v.584-585, p.339-347, 2017. DOI: http://doi.org/10.1016/i.scitotenv.2016.12.150

TORRES, J. L. R.; CORDEIRO, T. S.; NASCIMENTO, C. A. O.. Avaliação do plano de recuperação de áreas degradadas implantado numa área de construção de torres e linhas de transmissão de energia. In: SIMPÓSIO NACIONAL DE RECUPERAÇÃO DE ÁREAS DEGRADADAS, 7. Anais. Curitiba: FUPEF, 2008. p.115-134.

WANG, M.; DUAN, L.; WANG, J.; PENG, J.; ZHENG, B. Determining the width of lake riparian buffer zones for improving water quality base on adjustment of land use structure. Ecological Engineering, v.158, n.106001, 2020. DOI: http://doi.org/10.1016/j.ecoleng.2020.106001

A CBPC - Companhia Brasileira de Produção Científica (CNPJ: 11.221.422/0001-03) detém os direitos materiais desta publicação. Os direitos referem-se à publicação do trabalho em qualquer parte do mundo, incluindo os direitos às renovações, expansões e disseminações da contribuição, bem como outros direitos subsidiários. Todos os trabalhos publicados eletronicamente poderão posteriormente ser publicados em coletâneas impressas sob coordenação da Sustenere Publishing, da Companhia Brasileira de Produção Científica e seus parceiros autorizados. Os (as) autores (as) preservam os direitos autorais, mas não têm permissão para a publicação da contribuição em outro meio, impresso ou digital, em português ou em tradução. 